\title{
Research on the Green Energy Technology of realizing Jinan Baotu Spring Park`s lawn evergreen in Winter
}

\author{
Yu hongtao \\ Jinan,shandong province,China \\ 158740904@qq.com
}

\begin{abstract}
Keywords: Lawn growth in Winter;Green energy;Lawn heater equipment
Abstract. In Winter, due to the cold weather, the most of cities' landscape in northern China are in the "Semi-abandoned" status. Yellow vegetation, frozen water and idle facilities, these kinds of landscape effect is difficult to match the goal of landscape design. The study found that plant growth is not only related to its life attributes, but also affected by the temperature, ground temperature, terrain and other external factors.

This article, through analyzing the lawn landscape of Jinan Baotu Spring, realized evergreen in winter by using the green energy of spring water, and insulated device (Patent Number: 201320335721.9) of maintaining the northern region lawn evergreen in winter, which provides a set of feasibility solutions to the northern landscape to achieve "winter spring" for the northern landscape.
\end{abstract}

\section{Introduction}

The division of the south and the north of China is generally based on the Qinling-Huaihe River line, since the temperature in the north of the boundary in winter is generally below $0^{\circ} \mathrm{C}$, and the south of the boundary is generally above $0{ }^{\circ} \mathrm{C}$. Most of the northern part in winter is cold and dry with a "thousands of miles of frozen, vegetation withered" scene. This monotonous earth landscape is depressing and boring, a variety of artificial landscape is basically in a semi-dormant state.

Since ancient times, the northerners are looking forward to getting type of "Saibei Jiangnan" landscape, however, under the constraints of natural conditions, this landscape effectn can not often be met.

As the historical city of northern China, because of a large number of springs, in cold winter, many Jinan citizens are still able to see the bridge of the water scene, moat water mist curl, there are quite some taste of "China Jiangnan". Famous writer Lao She, also surprised by the water features of Jinan (not frozen), wrote a well-known masterpiece "Jinan Winter". If you want to get effect of a small bridge flowing water, and green vegetation, Jinan is a natural one of them.

Lawn as an important element of landscape plants, the temperature of its growth depends less on the temperature but more on the temperature of the turf soil. The research found that if the temperature of the soil in the lawn root can be between $15-25^{\circ} \mathrm{C}$, the turfgrass can continue to grow and keeping green. The spring water temperature in Jinan Baotu Spring is always at $18^{\circ} \mathrm{C}$, if we can use the heat of spring water to supply lawn soil, we can meet the growth of lawn in the winter, thereby achieving the great effect of bridges flowing water and a luxuriant growth of grass effect in winter in Baotu Spring Park, which not only can meet people's desire for the warmth in the winter, but also can prevent wind and sand, improve air quality and other ecological effects.

\section{General situation of research place}

Jinan is located in the middle of Shandong (latitude $36^{\circ} 40$, longitude $117^{\circ} 00$ ), the three sides of the ancient city is surrounded by mountains, with the Yellow River flowing in its north, and the southern mountains connected with Taishan, the topography of the whole town is slightly basin-shaped. It belongs to temperate continental climate. Winter and summer time is long, while spring and autumn time is short. The annual average temperature is $14{ }^{\circ} \mathrm{C}$, the annual average rainfall is $650-700 \mathrm{~mm}$. January is the oldest, with the average temperature is $-0.2{ }^{\circ} \mathrm{C}$ and July is the hottest, with the average temperature is $30.4{ }^{\circ} \mathrm{C}$. Baotu Spring Park is located in Jinan City, which is one of China`s top ten outstanding gardens in China. 
The description of Baotu Spring can be traced back to the earliest 3543 BC, and the current spring pool was built by the great writer Zenggong of Song Dynasty. The Emperor Qianlong of the Qing Dynasty wrote "The finest Spring" on the monument which is still standing on the north side of Guanlan Pavilion. The Baotu Spring is the main scene of park. The spring pools east and west with the length of 30 meters, and from north to south, its width is 20 meters. The water pours out on the ground with three springs, the water from which is clear.

The spring pool is surrounded by large pieces of masonry, ringing to the handrail. You can lean on the fence to overlook the wonder scene of three spring spewing.

Baotu spring water gushes from the underground limestone cave, its maximum surge reaches to 240,000 cubic meters per day, and the exposing height is up to 26.49 meters. The water temperature of Baotu spring is at about $18{ }^{\circ} \mathrm{C}$ at all year round. In Winter, spring pool is gas curl, like a layer of thin smoke. On side is spring pool, deep, and sparkling, the other side is the castle painting, carved beams. They constitute a wonderful paradise on earth, and the locals call it "Cloud fog".

The vegetation of Baotu Spring Park is mainly composed of trees, shrubs and lawns. Arbors are based on the "weeping willow" of Jinan city, and mixed with pine trees, cypress trees, poplar, white wax, maple trees, locust trees and a small amount of fruit trees. Shrubs are mainly holly and lobular boxwood and turfgrass more varieties of poa pratensis. Like other cities in northern China, in winter, except pine and cypress ,the other trees of Baotu Spring will fall leaves, lawn yellow, and a bleak scene.

\section{The cause of formation of Baotu Spring}

\section{Topographic factors}

Three sides of Jinan city are surrounded by mountains. The north is the Yellow River. The city looks like a basin. The surrounding rain is mainly water supply of underground river. Especially in the southern mountains, warm and humid air in summer is under the elevation of hillside and cold form of abundant terrain rain. It brings a wealth of water to the Jinan spring water system. Due to around high and middle low, water flows to the lower. In the principle of connector, the urban rock forms a flowing well. Therefore, there is a Baotou spring water spewing landscape effect.

\section{Geological tectonic factors}

There are different opinions about the source of spring water since ancient times. In the 90's of $20^{\text {th }}$ century the experiment proved that Jinan spring water is from the southern mountains. The southern mountainous areas are dominated by limestone ,because of the small density, the lave and cave formed after erosion by water, and becomes the main channel of underground river. While the northern Jinan rock stratum is the gabbro, with high density, hard and anti-erosion. The South water can not further infiltration and must return to form the self-drilling effect. In addition, in the process of flowing on the limestone, the temperature goes higher due to the release of heat from the limestone. So the temperature maintains at $18{ }^{\circ} \mathrm{C}$ in the all year around.

\section{Temperature, ground temperature and the influence of turgrass growth}

\section{Temperature, ground temperature and mutual relationship.}

Atmospheric temperature is mainly affected by solar radiation and ground radiation. Ground temperature is affected by both solar radiation and temperature. During the daytime with the increase of the solar radiation intensity, the temperature and the ground temperature all began to rise. Due to the different thermal conductivity of air and soil, the improvement of the ground temperature was slower than air temperature. After the Sunset, the radiation of sun basically disappeared, but because the air temperature is still higher than ground temperature at this time, the atmosphere will still transmit heat to the ground. When the two sides are equal, the heat conduction will stop. With the decline of atmospheric temperature, the soil began to conduct heat the atmosphere in night, called the ground radiation. In a word, due to the temperature difference between the atmospheric heat and soil 
heat, their heat conducts with each other in the day and night. Because of the different composition of air and soil, the accumulation capacity of heat is different, the soil has better heat storage capacity than air, and increases with depth. According to determination, from the surface down $70 \mathrm{~cm}$, its ground temperature is greatly affected by the atmosphere and solar radiation, and downward further is the constant temperature layer. Due to the diversity of soil and address structure, the ground temperature varies from place to place, and changes are extremely rich, so it is difficult to obtain uniform data, only according to the local situation.

In general, the temperature is high during the daytime and at night it is low. From the whole year, it is higher in the summer and in winter it is low. Because the soil has a certain heat storage capacity, and the ground temperature change is seldom relative to the atmospheric temperature. The level of ground temperature is close to plant seed development and growth. Atmospheric temperature and ground temperature have a mutual conducting relationship. The atmospheric temperature fluctuates as the ground temperature goes up and down for a long time The ground surface temperature is particularly evident.

Form 1: The average temperature relationship between atmospheric temperature and ground temperature in winter and summer, in day and night.

\begin{tabular}{|l|l|}
\hline In Summer & Atmospheric temperature $>$ Ground temperature \\
\hline In Winter & Atmospheric temperature $<$ Ground temperature \\
\hline At day & Atmospheric temperature $>$ Ground temperature \\
\hline At night & Atmospheric temperature $<$ Ground temperature \\
\hline
\end{tabular}

\begin{abstract}
Atmospheric temperature and ground temperature effects on lawn growth
As China is located in the northern hemisphere, in winter, the sun directs southern hemisphere, solar radiation for the northern hemisphere relative angle becomes smaller, air and ground to receive solar radiation intensity weakened. In addition, the Siberian cold air pushed by northwest wind and northeast wind and attack in most parts of northern China. The climate is cold and dry. With the decline of temperature, the ground surface temperature also decreases. In continuous low temperature after snow and even the surface soil freezing, this brings the plant severe challenges. The most of shrubs have fallen leaves, relying on the root temperature to maintain life and into the hibernation period. Even though the pine and cypress, holly do not fall leaves, stop growing and the crown is gray. Turfgrass is also yellow at this time, if the root can keep warm and next spring can be renewable, if the root can not maintain a certain temperature, large lawn will freeze to death.
\end{abstract}

The landscape turf grass species that Chinese cultivated, in accordance with climate conditions and geographical distribution, can be divided into two types: one is for cold season and the other for warm season. Warm season turf grass with strong thermal resistance is widely cultivated in the south of the Yangtze River in southern China. The cold Seasonal grass has strong cold resistance, and green period is longer (some cold season grass` green period can up to 220-250 days) cultivated by the northern region. For example, Poa pratensis, tall fescue, and bermudagrass are commonly used in cold places. The suitable temperature of the grass, stems and leave are at $12-15^{\circ} \mathrm{C}$, and grassroots growth of the appropriate temperature is at $2-15^{\circ} \mathrm{C}$. The lawn in Baotu Spring Park basically belongs to this category. The lawn is mainly composed of three parts of the grass, root, leaves, and soil. Turf grass roots can reach deepest below $30 \mathrm{~cm}$ of ground. This layer of soil is affected greater by temperature changes. If the ground temperature of grassroots growth can be maintained at 2-15 ${ }^{\circ} \mathrm{C}$, they can be maintained alive. When the temperature is at $12-15^{\circ} \mathrm{C}$, the grass leaves can grow.

It can be seen that the growth of the lawn is mainly affected by the atmospheric temperature and ground temperature. The ground temperature has a greater effect on the growth of the lawn roots, and the grass leaves are more affected by the atmospheric temperature. 


\section{Technical conception and simulation experiment of realizing the Baotu park lawn green in winter}

\section{Technical ideas}

Since the temperature that the lawn root need to grow is at $2-15^{\circ} \mathrm{C}$, it is shown that the root system of the lawn will not be frozen at this temperature and the suitable temperature of the stems and leaves will be $15-24{ }^{\circ} \mathrm{C}$, which will make the lawn keep green. In the winter, there is a sun at noon, the temperature is likely to reach $15-24^{\circ} \mathrm{C}$. In winter, the water temperature of Baoto Spring can still be maintained at $18{ }^{\circ} \mathrm{C}$, if using a device to collect water and placing device under the surface of the lawn, it is equivalent to adding a "hotbed"to the lawn. The continuous and constant temperature of the water can heat turf soil constantly so that the lawn can obtain the appropriate growth temperature. If the idea is feasible, we can achieve the lawn green.

Lay warm pipeline under the surface of $30 \mathrm{~cm}$, the pipeline entrance and outlet are connected with the spring pool. Use water pump to make Baotu spring water into the warm tube so that $18^{\circ} \mathrm{C}$ spring water flow in the pipeline by circulation. In the process of flowing, because the soil temperature is lower than the pipeline water temperature, the heat exchanging happens between water pipe and the soil. The soil temperature will rise.

If the soil temperature can rise to $12-15^{\circ} \mathrm{C}$ through the heat release of warmer pipe, then the grass roots can grow. When ground temperature to $15^{\circ} \mathrm{C}$, the grass stems and leaves can grow so as to keep the Baotu Spring park present green landscape and vitality in winter.

\section{Simulation experiment}

In order to verify whether this idea can be achieved, the writer of this paper conducted an experiment in wintert, simulating water temperature and site conditions of Baotou spring. The experimental methods, procedures and process are as follows:

Setting constant temperature water tank: taking foam turnover box as a water container, inlet and outlet were connected with the warm tube separately. At the outlet installed a $10 \mathrm{~W}$ pump, so that it can make water into the pipeline; a $1500 \mathrm{~W}$ heating rod was installed in the tank, with the heating rod power controlled by the thermostat, and the heating maximum temperature is set to $18^{\circ} \mathrm{C}$ (as shown); Using this constant temperature water to replace the Baotu spring water for testing.

Experimental grass: On a land of $2.5 \mathrm{~m}$ x $8 \mathrm{~m}$, dig a $30 \mathrm{~cm}$ square pond from the surface, lay the PECT warm pipe ( $\mathrm{S}$-shaped), cover soil on warm pipe and put grass on the soil. The another land is not using the ground temperature heating device, compared two turfgrass growth in winter.

setting the thermometer: from the surface below $30 \mathrm{~cm}$ and up every $5 \mathrm{~cm}$ set a thermocouple temperature probe, until to the tip point of grass leaves(As shown in the figure). And recording the temperature data displayed in the day before (Beijing time 7:00), in (Beijing time 14:00,), late (Beijing time 20:00). (Figure 1:Setup diagram of greensward temperature sensors)

\section{Experimental Location and Time:}

November $15^{\text {th }}, 2012$ - March 15 ${ }^{\text {th }}, 2012$

November $15^{\text {th }}, 2013$ - March $15^{\text {th }}, 2014$

Experimental Location: Jinan 
Setup Diagram of Greensward Temperature Sensors

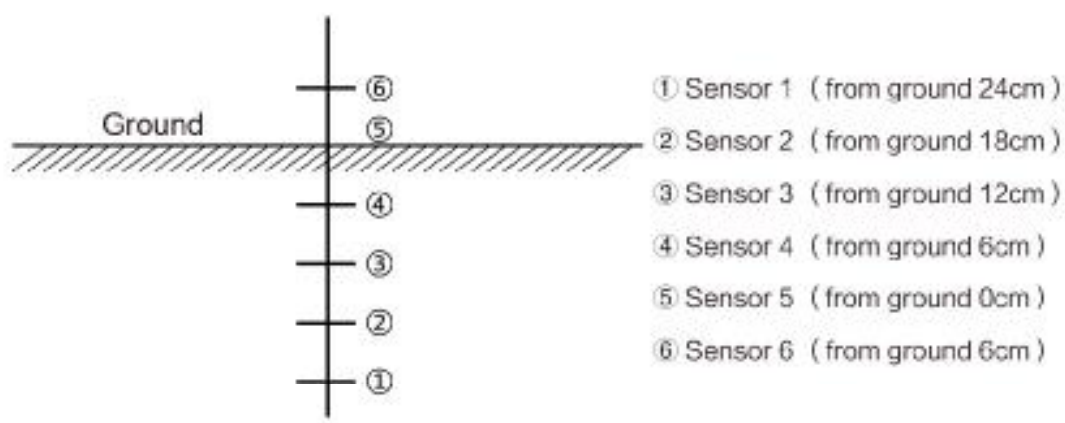



Figure 1:Setup diagram of greensward temperature sensors

\section{Experimental results and analysis}

to maintain the evergreen landscape effect: Through a winter experiment, the entire winter lawn can grow normally, showing a green. According to the experimental data can be seen, the experimental period of the coldest temperature reached $-15^{\circ} \mathrm{C}$, lawn did not appear frostbite. . At the beginning of March, the experimental area lawns back to green and the normal lawn is still dormant.

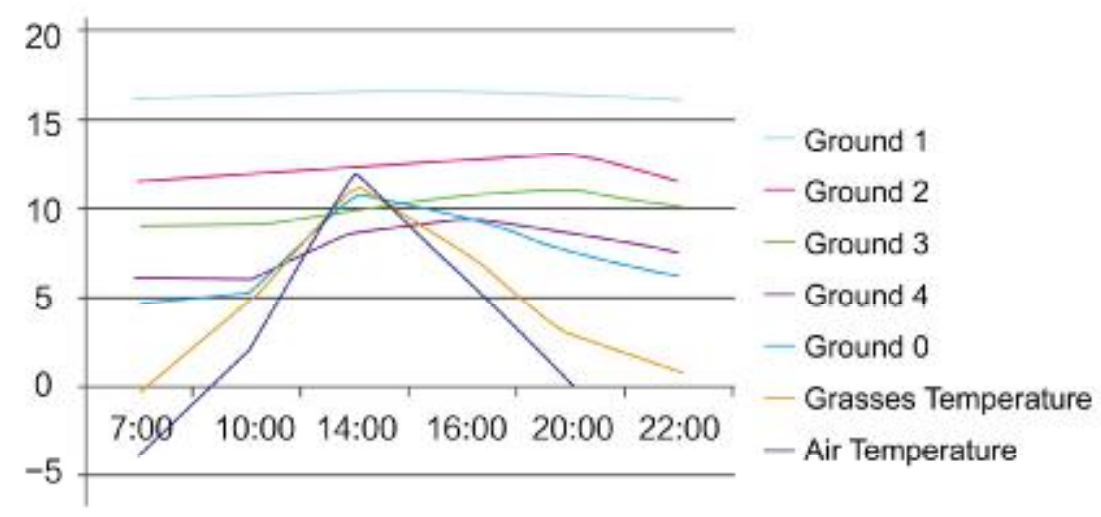

Figure 2: February $19^{\text {th }}, 2013$ Changes of soil temperature, grass temperature and temperature at different times within a day.

Different time in one day, the ground temperature 1is basically constant, showing that the average temperature of the whole winter is $17.6^{\circ} \mathrm{C}$, while the average annual temperature in Jinan is about $15{ }^{\circ} \mathrm{C}$, which proves that $18{ }^{\circ} \mathrm{C}$ "spring water" worked. From the thermometers 1 to 6 , the ground temperature showed a decreasing trend, and the calculation methods of soil heat transfer coefficient are basically consistent with those measured by Gaoqing. The average reduction of $2{ }^{\circ} \mathrm{C}$ per $5 \mathrm{~cm}$, so 
that if you want to get a good effect of winter lawn growth, you need try to make the heated water pipe close to the lawn roots. However, winter lawn grass growth too high may lead to stems and leaves frostbite phenomenon, so must make lawn pruning in winter.

Thermometer 6 (grass tip position) is slightly higher than the temperature of about $10 \%$, which shows that the lawn itself has a certain insulation function.

5.2.2 from the early morning to evening micro-observation: ground temperature 1,2,3 test point, the temperature is relatively stable throughout the day, which has relation to two aspects of continuous heat and soil thicker with good heat preservation. And close to the ground 4,5,6 test point as big space from the heating, and soil thin, affected by the solar radiation and atmospheric temperature large and changes significantly.

\section{Conclusion}

Through the above experiments proved that to achieve winter lawn evergreen is entirely feasible. This program use the Baotu spring water heat, making cycle heating system for the lawn temperature. Baotu spring water in addition to its effective use of the heat, the nature of the water did not any changes. This green energy will not increase carbon emissions, the use of electricity is limited to the pump. It is very economical. By using of this low-carbon, low-energy system to achieve the lawn temperature rise, and the lawn can continue to grow in the winter, so as to maintain a green, bring boring winter a sense of spring. So that winter landscape effect greatly improved to meet people's desire for green life. Due to the growth of the lawn produced a new ecological effect: During the process of the lawn growth releases oxygen to improve the air quality of small environment. At the same time, play a good role in wind prevention and sand fixation. There are lots of similar waste energy in our life. This article is only adjusting measures to local conditions, with the help of winter Baotu spring heat, to achieve the spring landscape effect. But this does not mean that only Baotu Spring can achieve the evergreen landscape, as long as can find the excess heat in winter, and to increase the ground temperature to the lawn can achieve this effect. For example, if the hot water pipeline in the northern can lay from the lawn into the building, the normal loss of heat during transmission can provide the roots heat, so then keep the grass green. Of course, this also requires landscape designers to carry out the design and planning can be effectively achieved. Although only to do such a technological revolution for lawn evergreen, but giving a new meaning to the winter landscape in the ecological, visual, psychological, environmental and other angles.

\section{References}

[1] Zhang Zhiguo,Li Weide:Mordern Lawn management.China Forestry press (2003), p.72.

[2] Dai Yongxia: Spring Culture.Shandong Friendship Press 2012, p.4 and 7.

[3] Sun Benxin, YI Gong,Zhang Jing:Lawn plant cultivation technology.Beijing China Forestry Press 2001,p.9,p.13,p.72.

[4] Gao qing Yu Chuanhui Ma Chunqiang Yu Ming,Xuan Zhehao:Analysis of influencing factors on determination of thermal conductivity of underground soil.Journal of Solar Energy Vol.29 No.5 May 2008. p.581-585.

[5] 7.Deng Tianhong,Wang Guoan,Jiao Jianli, Yu Hui : Grass temperature, Ocm ground temperature, temperature changes law.Meteorology and Environmental Science, Volume 32, No. 4, November 2009, p.47-50. 